\title{
Efeitos da ilustração do livro de literatura infantil no processo de leitura ${ }^{1}$
}

\section{Effectiveness of children's literature illustration in the reading process}

\author{
Flávia Brocchetto Ramos ${ }^{2}$ \\ Marília Forgearini Nunes ${ }^{3}$
}

\begin{abstract}
RESUMO
O livro de literatura infantil pode ser caracterizado pela presença da ilustração associada à palavra. No entanto, avaliar se essa ilustração possui um valor artístico-estético que, no processo de leitura, amplia as possibilidades de construção de sentido ou, se o trabalho do ilustrador serve somente para dar cor e forma ao verbal sem agregar-lhe sentido, são dúvidas que podem surgir na análise desse tipo de texto, diante da diversidade de obras infantis. Esse estudo busca responder a essa questão a partir da descrição e análise da capa de duas edições - publicadas em 1991 e 2003 - da obra Ah, cambaxirra se eu pudesse..., um conto popular adaptado por Ana Maria Machado, e ilustrado por Gerson Conforto e Graça Lima respectivamente. A partir dessa análise discutem-se os conceitos de arte e estética (CROCE, 2001; FIORIN, 1999; HUISMAN, 1994), bem como o processo de leitura a partir da relação ilustrador-leitor sob a perspectiva da experiência da leitura mediada (ISER, 1979) e da semiótica (GREIMAS; FONTANILLE, 1993; GREIMAS, 2002). Ao final, procura-se apontar caminhos para responder à pergunta que originou esse estudo, de modo que a ilustração do livro infantil
\end{abstract}

${ }^{1}$ Estudo realizado no contexto de pesquisa apoiada pelo Edital MCT (Ministério da Ciência e Tecnologia)/CNPq (Conselho Nacional de Desenvolvimento Científico e Tecnológico)/MEC (Ministério da Educação e Cultura)/CAPES (Coordenação de Aperfeiçoamento de Pessoal de Nível Superior) n. ${ }^{\circ}$ 02/2010 - Ciências Humanas, Sociais e Sociais Aplicadas.

${ }^{2}$ Doutora em Letras pela Pontifícia Universidade Católica do Rio Grande do Sul (PUCRS). Professora e pesquisadora na Universidade de Caxias do Sul no Programa de Pós-Graduação em Educação e Programa de Pós-Graduação de Letras (PPGEd/PPGL), Caxias do Sul, Rio Grande do Sul, Brasil. E-mail: ramos.fb@gmail.com

${ }^{3}$ Doutoranda em Educação pela Universidade Federal do Rio Grande do Sul (UFRGS), Rio Grande do Sul, Brasil. Bolsista CNPq.E-mail: mariliaforginunes@gmail.com 
seja avaliada a partir da construção de sentido decorrente da relação leitor-texto no processo de leitura da ilustração.

Palavras-chave: ilustração; literatura infantil; leitura.

\begin{abstract}
Child literature books can be characterized considering the existence of illustrations associated to words. However, when evaluating if illustrations have an artistic-esthetic value which, in the reading process, can increase the meaning construction possibilities or if the illustrator work gives only color and shape to the verbal part without offering any new meaning possibility, those are doubts that can arise during the analysis of this kind of text considering the great diversity of published titles. This study aims to answer that question based on the description and analysis of the book cover from two different editions - 1991 and 2003 - of Ah, cambaxirra se eu pudesse..., a popular short story adapted by Ana Maria Machado, and illustrated by Gerson Conforto and Graça Lima respectively. Based on this analysis the concepts of art and aesthetics (CROCE, 2001; FIORIN, 1999; HUISMAN, 1994) are made, and also concerning the reading process and the relation between the illustrator and the reader in the perspective of a mediated reading experience (ISER, 1979), as well as in the semiotics point of view (GREIMAS; FONTANILLE, 1993; GREIMAS, 2002). In conclusion, some directions are outlined in order to answer the question that guided this study. Those directions pointed to the idea that the illustrations of a child literature picture book can be evaluated taking into account the constructed meaning resulting from the interaction reader-text in the illustration reading process.
\end{abstract}

Keywords: illustration; child literature; reading.

Palavra de um artista tem que escorrer substantivo escuro dele.

(Manoel de Barros)

Este estudo começa a ser delineado a partir de algumas dúvidas: afinal, que ilustração presente no livro infantil pode ser considerada artisticamente de qualidade, de modo que efetue uma recriação e não uma mera reprodução da realidade ou, talvez, construa um estereótipo dessa realidade para as crianças? $\mathrm{E}$, além disso, de que modo o ponto de vista do ilustrador modaliza o texto verbal e influencia na experiência interativa do leitor com o texto - verbal e visual? 
Para que se tente chegar a alguma solução, não conclusiva, mas que permita ao menos estabelecer argumentos que auxiliem na construção de uma possível resposta, o presente estudo tentará articular os conceitos de arte e de estética com o processo de leitura a partir da análise do trabalho de dois ilustradores em duas edições de uma mesma história popular veiculada em obras que visam ao público infantil. O objetivo desta discussão a respeito de arte e estética em relação ao ato de ler será o de tentar estabelecer um vínculo desses conceitos com as ilustrações analisadas, do modo com que se apresentam em termos de forma e conteúdo - oferecendo ao leitor maior possibilidade de interação com o texto e, consequentemente, o seu desenvolvimento crítico e criativo.

A narrativa $A$, cambaxirra se eu pudesse... é um conto popular, adaptado para a linguagem escrita por Ana Maria Machado. Neste estudo, utilizam-se duas versões diferentes da mesma obra. A primeira versão, por ordem cronológica, foi publicada no ano de 1991 pela editora Salamandra e ilustrada por Gerson Conforto e fazia parte da coleção Conte outra vez. A segunda versão foi publicada pela editora FTD, no ano de 2003, e é ilustrada por Graça Lima e faz parte da coleção Conta de novo.

A narrativa que sobreviveu pela oralidade, agora recebe uma forma escrita associada a ilustrações distintas em cada uma das edições. Acredita-se que a história perdura, porque o conflito posto pela ficção mantém-se atual, referendando que a literatura é um conhecimento indispensável aos seres humanos, ao fornecer a possibilidade de viver dialeticamente problemas, além de ordenar nossa mente e sentimentos e de focalizar situações de negação dos direitos humanos, tornando-nos "mais compreensivos e abertos para a natureza, a sociedade, o semelhante" (CANDIDO, 1995, p. 249).

No caso do conto escolhido, por meio da acumulação de fatos e de personagens que se repetem como um refrão, narra a história de um pássaro, a cambaxirra, mais conhecida por corruíra, que estava fazendo seu ninho na árvore de galho mais bonito da floresta quando, de repente, um lenhador aparece para cortá-la. A cambaxirra implora que ele não corte a árvore, mas ele diz estar obedecendo às ordens de alguém e que nada pode fazer, pois tem medo dessa pessoa. O pássaro não desiste de salvar a sua árvore e, consequentemente, seu ninho, e busca o capataz para pedir que ele impeça o lenhador de cortar a árvore. No entanto, o capataz também está obedecendo às ordens de outro, do barão, que obedece ao visconde, que por sua vez obedece ao conde. A ave-protagonista, mesmo tendo que percorrer todas essas pessoas e seus demais superiores como o marquês, o duque, até chegar ao imperador, o mais poderoso de todos, não desiste de salvar a sua árvore.

Esses fatos são apresentados pela palavra que dialoga com as imagens ilustradas desde a capa e ao longo das páginas de ambas as edições. No entanto, não identificamos semelhança na maneira com que esse diálogo se dá em cada 
um dos exemplares, pois há diferença na forma e no conteúdo das ilustrações, o que altera o processo de leitura - interação do leitor com o texto ilustrado.

A partir desse ponto, propõe-se a análise da capa nas duas edições da narrativa $A$ h, cambaxirra se eu pudesse... (Fig. 1 e Fig. 2). A análise será associada à discussão a respeito das características artísticas da ilustração no livro infantil a partir do ponto de vista do ilustrador que modaliza o texto verbal e apresenta-o ao leitor sob uma nova ótica, proporcionando, assim, uma nova leitura/interação. Essa discussão será feita com base em teóricos como Huisman (1994), Bernardo (2005), Croce (2001), Fiorin (1999) e Greimas e Fontanille (1993). Optou-se por uma análise da capa por ser este apenas um breve estudo sobre a questão artística no processo de leitura da ilustração do livro infantil e, além disso, por ser a capa a porta de entrada do texto para o leitor.

\section{$O$ ponto de vista do ilustrador: caminho aberto para a interação do leitor com o texto}

Ana Maria Machado adaptou da oralidade para o código verbal escrito a narrativa tradicional a respeito da persistente cambaxirra. Os ilustradores Gerson Conforto e Graça Lima revelaram propostas de entendimento, por meio de ilustrações que dialogam com o código verbal. Cada um dos ilustradores, a seu tempo, foram leitores dessa narrativa e, portanto, expressam em seus trabalhos o seu ponto de vista a respeito da história, convidando o leitor a conhecer o enredo e o modo de dizê-lo, também a partir das imagens produzidas por eles.

No entanto, mesmo que a ilustração seja proveniente da ótica do ilustrador, assim como a palavra é organizada pelo escritor, cada uma das linguagens tem uma função na construção discursiva, tentando estabelecer um vínculo com o leitor. Por isso, palavra e ilustração precisam acolher o leitor e permitir-lhe encontrar no texto uma brecha para dele fazer parte, interagir, interferir, exercendo o papel de leitor, aqui entendido como produtor de sentido.

Essa brecha pode ser definida, segundo Fiorin (1999, p. 117), como um modo de "fraturar discursivamente a ordem" propiciando ao leitor uma experiência verdadeiramente estética, função principal do texto literário. Portanto, a ilustração, como parte constituinte do texto literário, que é um objeto de arte, deve procurar ultrapassar a "realidade vulgar por meio de uma idealização, por mínima que seja" (HUISMAN, 1994, p. 74). A ilustração atrai o olhar do sujeito que se deslumbra e se volta sobre o que vê, para interagir com o texto, ou seja, com a nova realidade apresentada pela imagem. Em síntese, a ilustração con- 
vida o leitor a viver uma experiência estética, não se trata apenas de observar uma obra artisticamente executada, percebendo seus materiais ou técnicas de produção, mas de recebê-la, percebê-la, senti-la, deixar-se levar pela emoção que aquele conjunto, artisticamente constituído, provoca.

Dessa forma, a imagem criada pelo ilustrador, apesar de dirigir o "olhar [do leitor] para o ponto que o artista lhe apontou, [dá a possibilidade de olhar] pela fresta que ele abriu" (CROCE, 2001, p. 35), permitindo ao leitor enxergar o verbal a partir de uma outra ótica e criar novas imagens a partir da interação com o que vê/lê. E essas novas imagens permitem a passagem a um novo "estado das coisas", o deslumbramento que provoca a fratura na cotidianidade e atrai o olhar (GREIMAS, 2002, p. 26-27). A fresta aberta pela imagem, neste caso a ilustração, torna-se, portanto, uma brecha para viver experiências sensoriais, imaginativas, desafiadoras, estéticas e de total fruição.

\section{Capa: fresta que convida o leitor a espiar, entrar e se permitir viver a fruição/paixão}

A capa é a embalagem do livro e tem como função apresentar o leitor ao objeto de leitura, seduzindo-o para voltar o seu olhar a esse objeto (RAMOS; PANOZZO, 2005). As duas edições da narrativa Ah, cambaxirra se eu pudesse..., utilizadas neste estudo, apresentam elementos comuns na construção da capa, tais como ilustração, informações de autoria da palavra e da ilustração, assim como da editora que publicou cada uma das obras. No entanto, a sua concepção gráfica, isto é, a maneira com que cada um desses elementos se dá a ver é diferente e, portanto, ao leitor se oferecem duas experiências de interação/leitura singulares.

O nome da autora, nas duas versões (Fig. 1 e Fig. 2), encontra-se na posição superior e escrito com letras brancas. Porém, na primeira edição ele não fica tão destacado quanto na obra publicada em 2003, não pela cor utilizada nas letras, o branco, mas pelo plano de fundo que, na edição mais antiga, está sobre um detalhe da imagem que compõe a capa. Na edição mais atual, o plano de fundo na cor amarela emoldura a denominação da autora cujas letras para se destacarem no fundo amarelo receberam um sombreado dando-lhes tridimensionalidade e, consequentemente, melhor visualização. Essa indefinição no campo visual também aparece na grafia do título da obra na primeira edição, que é escrito em preto, porém também está sobreposto à ilustração. Nesse aspecto, percebe-se que na primeira edição, ao contrário da segunda, não há separação entre os campos visual e verbal o que pode dificultar a leitura do texto verbal. 


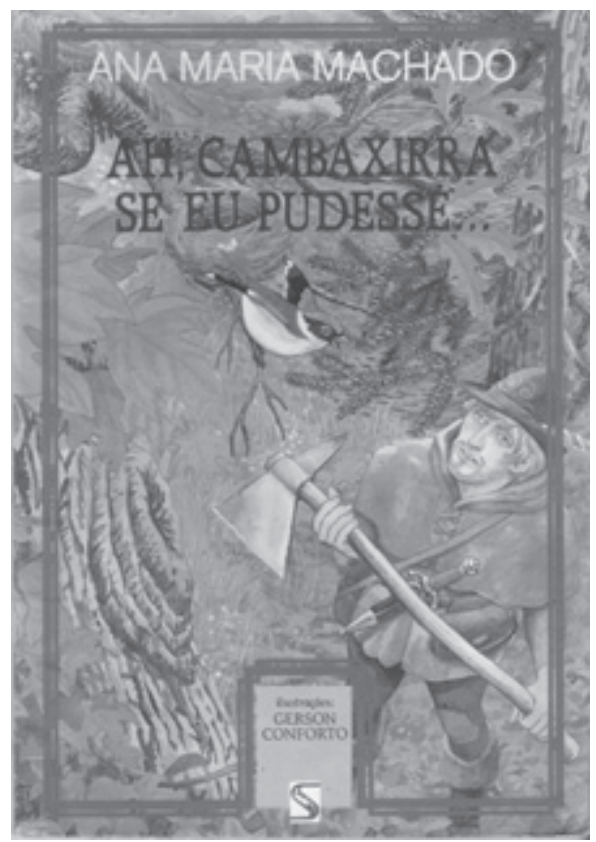

Figura 1 - Capa da edição de 1991, ilustrada por Gerson Conforto.

O segundo elemento, que pode ser encontrado em ambas as capas, é a referência aos ilustradores. Na primeira capa, por ordem cronológica, a indicação do ilustrador está localizada na parte inferior central. $\mathrm{O}$ tamanho da fonte utilizada é pequeno e o nome está escrito dentro de um retângulo cinza que encobre uma parte da ilustração. Nessa mesma posição, porém um pouco mais abaixo, visualiza-se o símbolo da editora. Na outra capa em análise, a mais atual, o nome da ilustradora também é encontrado na parte inferior, contudo, a ele ficou reservado o canto direito. Enquanto na primeira capa, o nome do ilustrador não foi escrito diretamente sobre a ilustração, na segunda, o nome de Graça Lima está disposto de modo ondulado sobre a ilustração, como um pintor que assina a sua obra, e o nome e o símbolo da editora ficam no canto inferior esquerdo.

A noção de que todos os elementos presentes na capa formam um conjunto de dados referentes à mesma obra, na primeira edição, é dada por uma moldura constituída de linhas verdes, cor que se mescla às cores da ilustração que dominam a capa. Na edição mais atual, essa mesma ideia pode ser identificada pelo fio que traz o nome da coleção à qual essa narrativa pertence e, também, o da ilustradora. Esse fio preto com a ponta em forma de espiral localizado nas 


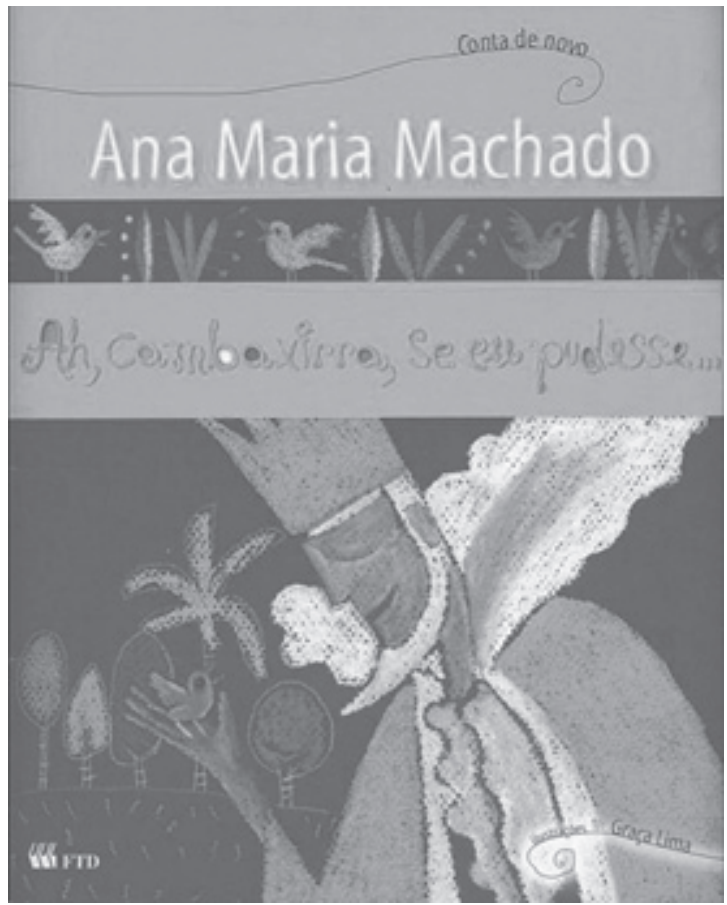

Figura 2 - Capa da edição de 2003, ilustrada por Graça Lima.

partes superior e inferior da capa representa a captura da atenção do leitor e um convite a esse sujeito para "abrir" o livro e procurar lá dentro mais elementos para complementar o que foi visto na capa.

O título da obra, como deveria ser, está presente nas duas capas, porém a sua maneira de apresentação é bastante diversa e amplia a discussão sobre o papel da visualidade na construção de sentido no processo de leitura (Fig. 3). Na edição de 1991, o título está pouco destacado, escrito em fonte de tamanho médio e com todas as letras maiúsculas na cor preta, ele se mistura à ilustração que preenche o plano de fundo. Uma leitura possível de ser feita é a de que, talvez, a diagramação da capa tenha escolhido privilegiar a imagem e não a palavra, mas isso não poderia ter prejudicado a identificação do título da obra. $\mathrm{O}$ mais adequado seria que tanto ilustração quanto palavra recebessem o seu destaque de modo a realizar o diálogo entre ambas na construção da capa que apresenta a narrativa.

Na segunda obra analisada, a de 2003, o título da obra recebeu maior atenção gráfico-estética. A começar pela posição, pois ao contrário da anterior, 

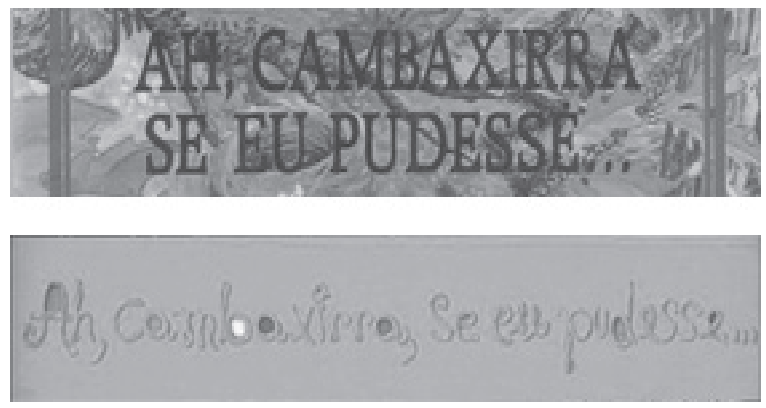

Figura 3 - Detalhe do título das edições de 1991 e 2003.

está localizado na posição central, emoldurado por um plano de fundo amarelo que se destaca por estar entre uma faixa decorativa e a ilustração principal cujas cores dominantes são escuras. Além disso, o modo com que o título está representado busca fugir do usual ao utilizar um tipo de letra cursiva, escrita por meio de um barbante amarelo mais forte do que a base, sendo possível perceber os fios mais finos que o compõem, sugerindo relevo e um caráter artesanal (RAMOS; PANOZZO, 2011, p. 77). A ilustradora, ao utilizar esse artifício para apresentar o título, interferiu de maneira criativa no modo com que a palavra se revela ao leitor, conferindo à capa, por meio da tridimensionalidade do barbante, uma maior possibilidade de atração do olhar do leitor e, consequentemente, de interação com o texto.

O último aspecto a ser analisado nessa comparação é a ilustração - elemento que domina toda a capa ou grande parte dela, convidando o leitor a conhecer a história que a capa anuncia. Essa ilustração traz o ponto de vista modalizador de cada ilustrador e interfere sensivelmente no processo de construção de sentido decorrente do ato de ler.

$\mathrm{Na}$ ilustração produzida por Gerson Conforto (Fig. 4), observa-se a presença de dois personagens, um pássaro, a cambaxirra, e um homem, o lenhador, identificado como tal pela presença do machado em sua mão. Os dois personagens estão numa floresta e lá se encontram. É possível perceber que há um ninho construído em uma árvore que não é visualizada por inteiro. Nesse ninho, localizado no centro da capa, está a cambaxirra ${ }^{4}$, com peito branco, e as asas com penas brancas, azuis, verdes e pretas, cabeça com o topo coberto de plumas vermelhas, olhos emoldurados pela cor preta e bico amarelo. O pássaro divide essa parte central com o machado do lenhador. Este segura o seu machado e

${ }^{4}$ A imagem da cambaxirra veiculada na ilustração dessa capa é muito distinta da ave real, cuja plumagem é predominantemente parda com pequenas faixas negras nas asas e cauda. 

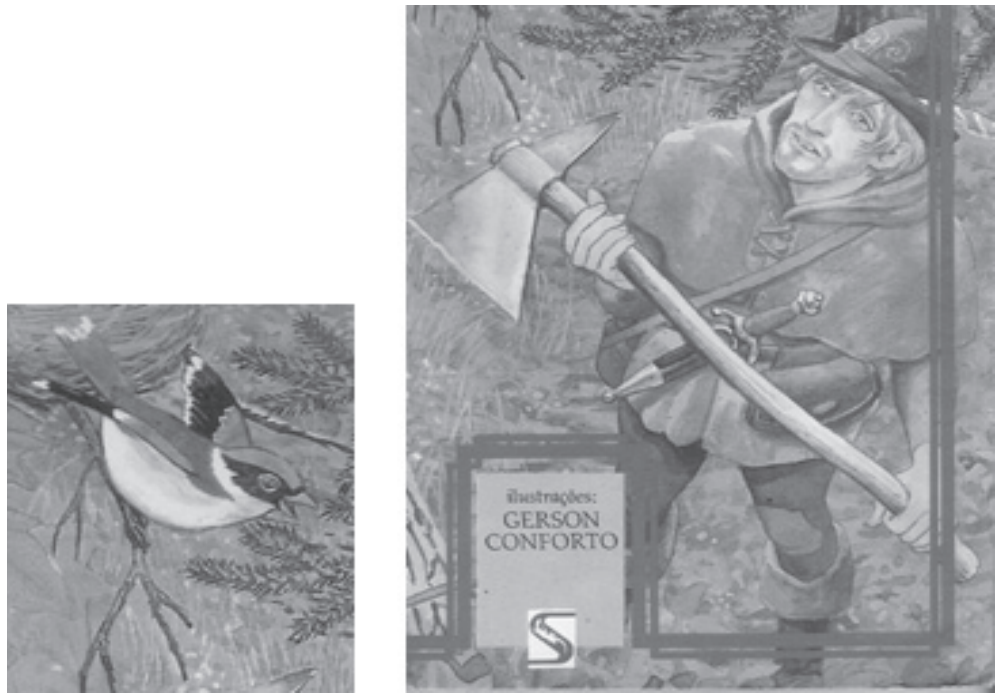

Figura 4 - Imagem da cambaxirra e do lenhador (1991).

volta o seu olhar para o pássaro que, representado com o bico entreaberto, parece estar se comunicando com o homem. Destaca-se que o humano, representado na capa, é o primeiro na sequência de personagens aos quais a cambaxirra pede ajuda para salvar a sua árvore.

Tanto o pássaro quanto o lenhador, com seu cabelo e barba loiros, olhos azuis num estilo europeu de representação da figura humana, tentam aproximar-se de traços do real. Da mesma maneira ocorre com o plano de fundo, a floresta, com árvores, folhas, terra e gramíneas em que a tonalidade e a textura procuram espelhar a realidade.

O espaço para recriação, nessa ilustração, é restrito, já que assume a postura de registro da realidade. Esse ponto de vista do ilustrador não busca subverter a realidade, dando ao leitor poucas possibilidades para ter outro ponto de vista. Assim como a ilustração domina o plano de fundo da capa, o sentido que o leitor pode construir a partir da sua leitura é mais fechado, restrito. Diante dessa imagem, o papel do leitor tende a ser o de observar e conhecer os personagens da narrativa e suas ações que facilmente podem ser descritas. Afinal, o que mais poderia estar acontecendo entre um homem segurando um machado próximo do tronco de uma árvore e um pássaro próximo de seu ninho? 
A capa da obra de 2003 (Fig. 5) reservou a sua metade inferior para a ilustração, evidenciando separação entre o cenário e os personagens destacados a partir da narrativa e dos dados contextualizadores como título e autoria. Nesse espaço, o leitor encontra: dois personagens e um local. Dois planos se distinguem, o primeiro, no qual o leitor vê um ser humano que pelo modo de se vestir e pela coroa em sua cabeça só pode ser um rei ou imperador e um pássaro com asas e bico entreabertos pousado sobre a mão do humano. O segundo plano, que se distingue do primeiro por seu aspecto inacabado - traços de contorno visíveis, ultrapassando os limites das figuras, pintura sem uniformidade e apenas em algumas partes da imagem (RAMOS; PANOZZO; ZANOLLA, 2011) apresenta algumas árvores caracterizando uma floresta.

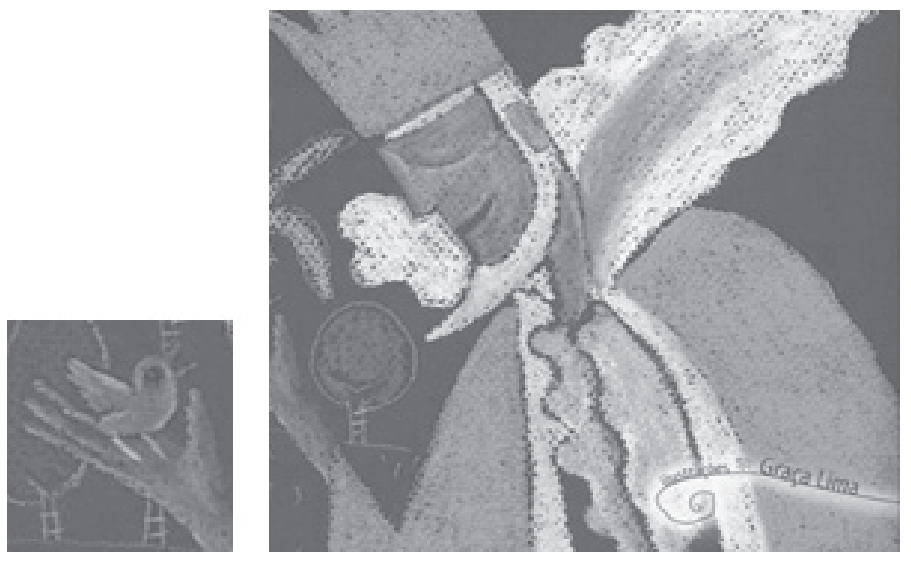

Figura 5 - Imagem da cambaxirra e do imperador (2003)

O modo com que os personagens estão representados no que diz respeito à forma, principalmente o imperador, subverte alguns estereótipos do desenho e da representação humana. As linhas de contorno não existem, essa função é exercida pela cor do plano de fundo. O rosto do imperador, com um nariz grande e disforme que parte de sua testa, os olhos fechados apenas delineados por uma linha descontínua de pequenos pontos pretos e a boca representada apenas por uma linha levemente curva na cor de fundo, mostram-se amigáveis, porém sem representar fielmente a feição humana. Tudo isso é completado pela coloração da pele que tem a sua representação nos tons de rosa. A mão disforme do imperador surge de um pulso fino e acolhe a cambaxirra com seu bico entreaberto, sugerindo uma situação de comunicação em que predomina a harmonia entre os personagens. Destaca-se que o imperador é o último indivíduo a quem a cambaxirra recorre no intuito de salvar a sua árvore. 
Esse conjunto de elementos veiculados na ilustração de Graça Lima na capa da obra amplia as possibilidades de construção de sentido e de experiência de deslumbramento e de fratura da realidade. A forma com que a ilustração se compõe - linhas imprecisas e subversão de estereótipos nas formas e nas cores utilizadas, por exemplo - concedem a essa imagem o valor de arte, pois une o criativo/sensível ao inteligível (CROCE, 2001). E, por ser compreensível, o conteúdo da imagem dá ao leitor uma visão a respeito da ação narrativa, permitindo que esse sujeito, por meio da leitura, construa um sentido para o que vê/lê. Essa imagem é, portanto, uma imagem artística, pois se vale da sensibilidade para ser compreendida e originar uma ideia (CROCE, 2001). Assim, os elementos visuais presentes na capa possibilitam ao leitor antecipar criativamente aspectos que podem ou não ser encontrados no miolo do livro, em um exercício de produção de sentido.

\section{Considerações finais}

Inicialmente, este estudo questionava-se a respeito de duas dúvidas: que tipo de ilustração do livro infantil poderia ser considerado artístico e esteticamente de qualidade no sentido de ser um objeto de arte que provoca no leitor a fratura, a mudança de estado de alma gerada pelo sentimento da paixão apontada por Greimas e Fontanille (1993) e não apenas cópia da realidade e, além disso, de que maneira o ilustrador a partir de seu ponto de vista influenciaria no modo de interação do leitor com o objeto de leitura, no caso a ilustração. Ao final deste estudo, a partir da análise e da discussão apresentada, chega-se primeiro à conclusão de que as duas questões, apesar de apresentadas separadamente, estão imbricadas.

O ponto de vista que o ilustrador apresenta ao leitor já demonstra o nível de valor artístico e, por consequência, da experiência estética que o leitor terá a oportunidade de vivenciar. Uma ilustração que apenas tenta representar a realidade pouco provocaria o leitor a investigá-la, a construir novos sentidos, pois tende a mostrar uma verdade a ser observada. No entanto, uma ilustração que, ao contrário, subverte estereótipos na sua forma e contradiz de alguma maneira o conteúdo da narrativa, poderia surpreender o leitor, exalar a paixão (GREIMAS; FONTANILLE, 1993) que o convida a ingressar num novo mundo, a construir sentidos, a vivenciar uma experiência de leitura estética.

Nas capas analisadas, cada ilustrador produziu a partir de sua leitura da narrativa uma visão, concedeu ao leitor uma porta para ele abrir e ingressar na 
história. Gerson Conforto traz ao leitor mirim uma representação segura da realidade. Graça Lima, no entanto, ao apresentar para o leitor uma cena nova, que inexiste na narrativa ilustrada, preferiu o arrebatamento da paixão que desconcerta, atrai o olhar, provoca a revisitação do que se mostra diante do olhar. O leitor, senão na primeira vista, mas durante ou após a leitura concluída, poderá retornar essa imagem, buscando construir um sentido, compreender que no início essa cena de harmonia entre o pássaro e o imperador é impossível, mas ao final do conflito ela torna-se real. A ilustração mais atual, portanto, amplia os sentidos, provoca o leitor a preencher um vazio, uma incerteza (ISER, 1979). E essa oportunidade de interagir com a narrativa por meio da ilustração confere a esse tipo de imagem o seu valor artístico e permite ao leitor vivenciar uma experiência de leitura estética condizente com o texto literário ao qual essa imagem ilustra.

Afirmar, portanto, qual das duas ilustrações tem mais qualidade significa ingressar em terreno perigoso, pois o que se tem são pontos de vista diferentes. Se há mais qualidade em uma do que em outra é difícil medir e este não é o foco deste estudo. O que se pode dizer, no entanto, é que uma ilustração plurissignificativa (BERNARDO, 2005) teria mais chance de que o leitor a reconstruísse a partir da interação, conferindo-lhe espaço para criar a partir do ponto de vista do ilustrador. A imprecisão/indefinição da imagem possibilitaria ao leitor não apenas observar, mas introduzir seu repertório na concretização do texto, de modo que provavelmente proporcionaria mais qualidade no processo de leitura da narrativa verbo-visual destinada à infância. Retoma-se a epígrafe deste texto para dizê-la de outra forma: uma imagem tem que ter substância de modo que alargue as vivências do leitor.

\section{REFERÊNCIAS}

BERNARDO, Gustavo. A qualidade da invenção. In: OLIVEIRA, Ieda (Org.). O que é qualidade em literatura infantil e juvenil? São Paulo: DCL, 2005. p. 9-24.

CANDIDO, Antonio. O direito à literatura. In: .Vários escritos. 3. ed. São Paulo: Duas Cidades, 1995. p. 235-263.

CROCE, Benedetto. O que é arte?. In: . Breviário de Estética. São Paulo: Ática, 2001. p. 31-51.

FIORIN, José Luiz. Objeto artístico e experiência estética. In: LANDOWSKI, Eric; DORRA, Raúl; OLIVEIRA, Ana Claudia de (Eds.). Semiótica, estésis, estética. São Paulo: EDC/Puebla: UAP, 1999. p. 101-117. 
GREIMAS, A. J. A fratura. In: . Da imperfeição. São Paulo: Hacker Editores, 2002. p. 21-65.

GREIMAS, A. J.; FONTANILLE, J. A epistemologia das paixões. In: Semiótica das paixões. São Paulo: Ática, 1993. p. 21-100.

HUISMAN, Denis. A estética. Lisboa: Edições 70, 1994.

ISER, Wolfgang. A interação do texto com o leitor. In: LIMA, Luiz Costa (Org.). A literatura e o leitor: textos de estética da recepção. Rio de Janeiro: Paz e Terra, 1979. p. 83-132.

MACHADO, Ana Maria. Ah, cambaxirra se eu pudesse... Il. Gerson Conforto. 2. ed. Rio de Janeiro: Salamandra, 1991. . Ah, cambaxirra se eu pudesse... Il. Graça Lima. São Paulo: FTD, 2003.

RAMOS, Flávia Brocchetto; PANOZZO, Neiva Senaide Petry. Acesso a embalagem do livro infantil. Perspectiva, Florianópolis, v. 23, n. 01, p. 115-130, jan./jul. 2005. 2011. . Interação e mediação de leitura literária para a infância. São Paulo: Global,

RAMOS, Flávia Brocchetto; PANOZZO, Neiva Senaide Petry; ZANOLLA, Taciana. Imagem e palavra na leitura de narrativa. Perspectiva, Florianópolis, v. 29, n. 01, p. 245-262, jan./jun. 2011.

Texto recebido em 14 de outubro de 2011.

Texto aprovado em 25 de abril de 2013. 